\title{
Efeitos de Sistemas de Manejo sobre a População de Tiririca ${ }^{1}$
}

\author{
Effects of Management Systems on Purple Nutsedge Populations (Cyperus rotundus) \\ JAKELAITIS, A. ${ }^{2}$, FERREIRA, L.R. ${ }^{3}$, SILVA, A.A. ${ }^{3}$, AGNES, E.L. ${ }^{3}$, MIRANDA, G.V. ${ }^{3}$ e \\ MACHADO, A.F.L. ${ }^{4}$
}

\begin{abstract}
RESUMO - Em experimento conduzido em campo, de novembro de 1998 a maio de 2001, sobre Argissolo Vermelho-Amarelo Câmbico de alta fertilidade, em Viçosa-MG, foram avaliados os efeitos de sistemas de manejo do solo na população de tiririca (Cyperus rotundus). Na área experimental, antes da instalação do experimento predominava infestação alta (720 \pm 130 plantas $\left.\mathrm{r}^{2}\right)$ de tiririca. Os tratamentos foram constituídos de dois sistemas de manejo do solo (plantios convencional e direto) e duas finalidades de uso da cultura do milho (grão e silagem), cultivados com feijão de outono-inverno em sucessão à cultura do milho, em blocos com quatro repetições. No plantio convencional, antes da semeadura das culturas, o solo foi arado e gradeado, e, no plantio direto, foi realizada a dessecação das plantas daninhas com glyphosate $+2,4-\mathrm{D}$. As avaliações das manifestações epígeas da tiririca na cultura do milho ocorreram aos 20 e 55 dias após a emergência (DAE) no ano agrícola 1999/00 e aos 20 DAE em 2000/01 e, para o feijoeiro, aos 20 e 40 DAE. A avaliação do banco de tubérculos foi realizada após a colheita do milho, no último ano de condução, determinando-se a densidade, a biomassa e a porcentagem de brotação dos tubérculos coletados. Verificou-se redução das manifestações epígeas da tiririca no sistema de plantio direto em ambas as finalidades de uso da cultura do milho durante todo o período de condução do ensaio. Tanto no milho cultivado para grão quanto para silagem, constatou-se elevada redução do banco de tubérculos no plantio direto, com predomínio de tubérculos dormentes, em relação ao plantio convencional.
\end{abstract}

Palavras-chave: herbicidas, plantios direto e convencional, Cyperus rotundus.

\begin{abstract}
A field experiment was conducted from November, 1998 to May, 2001 in a Cambic Yellow Red Argisol soil, with high fertility, in Viçosa, MG. The objective of this study was to evaluate the effects of soil management systems on purple nutsedge (Cyperus rotundus) populations. A high (720 \pm 130 plants $\left.\mathrm{m}^{-2}\right)$ nutsedge infestation prevailed in the experimental area before the installation of the experiment. The treatments consisted of two soil management systems (conventional and no-tillage) and two corn use purposes (grain and silage) cultivated with autumn-winter beans in succession to corn, in blocks with four replications. Under conventional tillage, the soil was moldboard plowed before planting, and under no-tillage, weed desiccation was carried out with glyphosate $+2,4-D$. The purple nutsedge population evaluations in the corn crop occurred at 20 and 55 days after emergence (years 1999/00) and at 20 days after emergence (years 2000/01), and in the beans crop at 20 and 40 days after emergence. The tuber bank was evaluated after corn harvest, during the last year, by determining density, biomass and percentage of sprouting of the sampled tubers. There was a reduction of purple nutsedge populations in no-tillage systems in both corn use purposes throughout the experiment. For both corn use purposes (grain or silage), there was a reduction in the tuber bank under notillage, with dormancy prevailing in comparison to conventional tillage.
\end{abstract}

Key words: herbicides, no-tillage and conventional tillage, Cyperus rotundus.

Recebido para publicação em 13.9.2002 e na forma revisada em 2.4.2003.

2 Pós-graduando, D.S., Dep. de Fitotecnia da Universidade Federal de Viçosa - UFV, 36571-000 Viçosa-MG; ${ }^{3}$ Prof. do Dep. de Fitotecnia da UFV, ${ }^{4}$ Estudante de Agronomia da UFV.

Planta Daninha, Viçosa-MG, v.21, n.1, p.89-95, 2003 


\section{INTRODUÇÃO}

A tiririca é considerada a planta daninha mais disseminada e agressiva de todo o mundo, provocando reduções quantitativas e qualitativas na produção mundial das principais culturas (Cudney, 1997). Na presença de condições ambientais favoráveis (temperatura elevada e intensa luminosidade), o seu estabelecimento é rápido, devido ao intenso crescimento vegetativo e à produção de tubérculos, razões primárias da sua vantagem competitiva com as culturas. Os tubérculos atuam como as principais unidades de dispersão, permanecendo dormentes no solo por longos períodos. Os diferentes "graus" de dormência dos tubérculos causam emergência irregular, e isso contribui para a persistência dessa espécie daninha no solo (Miles et al., 1996). Siriwardana \& Nishimoto (1987) relatam que, após seis semanas da emergência, os tubérculos produzidos já apresentam dormência, sendo maior com o aumento da idade.

Por apresentar rota fotossintética $\mathrm{C}_{4}$, a tiririca é altamente eficiente na assimilação do $\mathrm{CO}_{2}$ atmosférico e, conseqüentemente, na sua conversão em carboidrato. Todavia, para que as espécies $\mathrm{C}_{4}$ realizem com eficiência a fotossíntese, elas necessitam estar se desenvolvendo em condições de alta temperatura e luminosidade; portanto, a tiririca é pouco competitiva em condições de baixa temperatura e/ou intensidade luminosa (Silva et al., 2001). Em campo, o manejo da luminosidade é uma das ferramentas de maior importância no manejo integrado da tiririca. Sistemas de cultivo e técnicas culturais podem ser adotados para minimizar a quantidade de luz disponível para as plantas daninhas, pois a qualidade e intensidade de luz abaixo do dossel variam com a natureza das culturas e o arranjamento espacial das plantas (Mclachlan et al., 1993).

Segundo Ferreira et al. (2000), uma vez que a tiririca já tenha infestado uma área, é fundamental conter sua disseminação, o que pode ser conseguido por meio de cuidados especiais, como não revolver o solo (aração e gradagem). O revolvimento do solo pode separar os tubérculos dos rizomas, reduzindo a dormência e favorecendo a brotação. Assim, torna-se importante adotar métodos de manejo com os quais se obtenha o mínimo de distúrbio do solo, como o sistema de plantio direto, em que um pequeno revolvimento ocorre apenas no sulco de plantio.

Dentre os métodos de controle, o químico é o que tem apresentado os melhores resultados para redução da tiririca nas culturas de cana-de-açúcar e soja. Todavia, para as culturas de milho e feijão, assim como para a maioria das demais, não existem no mercado herbicidas que sejam seletivos e garantam controle aceitável da tiririca. Dos herbicidas sistêmicos nãoseletivos usados como dessecantes para o plantio direto, o glyphosate apresenta boa ação no controle da tiririca, pois pode se translocar até os tubérculos próximos ao bulbo basal, o que tem proporcionado redução significativa na rebrota após sua aplicação (Freitas et al., 1997).

No entanto, em razão da não-disponibilidade de herbicidas seletivos às culturas de milho e feijão que sejam eficientes no controle da tiririca, observa-se rápida reinfestação dessas culturas com essa planta daninha. O objetivo deste trabalho foi avaliar os efeitos dos sistemas de manejo do solo (plantios convencional e direto) e das culturas de milho para grão e silagem associadas ao feijão de outono-inverno em sucessão sobre a população de tiririca.

\section{MATERIAL E MÉTODOS}

O experimento foi desenvolvido durante três safras agrícolas, em Viçosa-MG, sobre Argissolo Vermelho-Amarelo Câmbico, textura argilosa e altamente fértil $\left(146 \mathrm{mg} \mathrm{dm}^{-3} \mathrm{de}\right.$ $\mathrm{P}, 141 \mathrm{mg} \mathrm{dm} \mathrm{m}^{3}$ de $\mathrm{K}, 3,4 \mathrm{cmol}_{\mathrm{c}} \mathrm{dm}^{-3}$ de Ca e 5,1 dag $\mathrm{kg}^{1}$ de matéria orgânica), onde predominava infestação alta de tiririca (Cyperus rotundus com $720 \pm 130$ plantas $\mathrm{m}^{-2}$ ). Os tratamentos foram constituídos de dois sistemas de manejo do solo (plantios convencional e direto) e duas finalidades de uso da cultura do milho (grão e silagem), dispostos em blocos com quatro repetições. A área total de cada parcela foi de $90 \mathrm{~m}^{2}(9 \times 10 \mathrm{~m})$, separadas entre si por bordadura de $1 \mathrm{~m}$. Em cada safra foram avaliadas as culturas de verão de milho para grão e silagem associadas à cultura do feijão, em sucessão. Embora tenham sido cultivadas três safras de milho e duas de feijão, foram apresentados e discutidos apenas os resultados a partir do segundo ano de condução do experimento. 
As semeaduras das culturas de milho para grão e silagem foram feitas em novembro/ dezembro de cada ano, sete dias após a dessecação das plantas daninhas com glyphosate + 2,4-D (1,44+0,335 $\left.\mathrm{kg} \mathrm{ha}^{-1}\right)$, nas parcelas onde se realizou o plantio direto. Nas áreas de plantio convencional não foi realizada a dessecação e o preparo do solo foi feito mediante uma aração e duas gradagens, para uniformização do terreno. Nos dois sistemas de condução da cultura do milho, a adubação de plantio foi de $32 \mathrm{~kg}$ ha de $\mathrm{N}, 112 \mathrm{~kg} \mathrm{ha}^{-1}$ de $\mathrm{P}_{2} \mathrm{O}_{5}$ e $64 \mathrm{~kg} \mathrm{ha}^{-1}$ de $\mathrm{K}_{2} \mathrm{O}$. Foram utilizados os híbridos AG-1051, BRS 3060 e AG-122, nos anos agrícolas 1998/ 99, 1999/00 e 2000/01, respectivamente, no espaçamento de $90 \mathrm{~cm}$ entre as fileiras, obtendo-se aproximadamente 67.000 plantas ha-1.

A aplicação dos herbicidas seletivos à cultura do milho foi feita aos 20 dias após a emergência (DAE), nos anos agrícolas 1998/ 99 e 1999/00. Foi aplicada a mistura de atrazine + nicosulfuron $\left(1,50+0,028 \mathrm{~kg} \mathrm{ha}^{-1}\right)$. No ano agrícola 2000/01 foi realizada a aplicação da mistura formulada de atrazine + metolachlor $\left(1,4+2,1 \mathrm{~kg} \mathrm{ha}^{-1}\right)$, em pré-emergência.

O milho para silagem, quando atingiu o estádio farináceo-duro, foi colhido mecanicamente e retirado da área, enquanto o milho para grão teve sua palhada incorporada ao solo no plantio convencional e espalhada na superfície do solo no plantio direto. O feijão cultivar Sangue de Boi foi semeado em abril/maio de cada ano, logo após a cultura do milho. As operações de manejo que antecederam o plantio foram semelhantes aos procedimentos descritos para a cultura do milho, exceto a dessecação das plantas daninhas realizada no plantio direto com o herbicida glyphosate $\left(1,44 \mathrm{~kg} \mathrm{ha}^{-1}\right)$. A adubação de plantio utilizada foi de $16 \mathrm{~kg} \mathrm{ha}^{1}$ de $\mathrm{N}, 56 \mathrm{~kg} \mathrm{ha}^{-1}$ de $\mathrm{P}_{2} \mathrm{O}_{5}$ e $32 \mathrm{~kg} \mathrm{ha}^{-1}$ de $\mathrm{K}_{2} \mathrm{O}$, sendo o espaçamento de plantio de $50 \mathrm{~cm}$ entre fileiras, com população aproximada de 230.000 plantas ha-1 . A aplicação da mistura formulada dos herbicidas fomesafen + fluazifop-p-butil $\left(0,175+0,14 \mathrm{~kg} \mathrm{ha}^{-1}\right)$ foi realizada aos $20 \mathrm{DAE}$.

Os efeitos dos tratamentos sobre a tiririca foram avaliados aos 20 e aos 55 DAE no ano agrícola 1999/00 e aos 20 DAE em 2000/01, na cultura do milho. Na cultura do feijão as avaliações foram realizadas aos 20 e aos 40 DAE. Foram feitas quatro amostragens ao acaso na parcela, utilizando um quadrado de $0,5 \mathrm{~m}\left(0,25 \mathrm{~m}^{2}\right)$, colhendo-se todas as manifestações epígeas da tiririca. Esse material foi levado ao laboratório, contado e seco em estufa com ventilação forçada por 72 horas a $70{ }^{\circ} \mathrm{C}$, determinando-se a biomassa seca.

A avaliação do banco de tubérculos no solo foi feita após a colheita do milho (2000/01), em cada parcela, numa área de 0,5 x 0,5 m, sendo os tubérculos coletados nas profundidades de 0-10, 10-20 e 20-30 cm. Esses tubérculos foram separados das demais estruturas vegetativas subterrâneas, contados e pesados. Após a pesagem, foram selecionados 20 tubérculos inteiros, sem danos mecânicos, rígidos e visivelmente viáveis, de cada tratamento e por profundidade, os quais foram plantados em vasos plásticos contendo $2 \mathrm{~kg}$ de areia umedecida com água. Após a brotação, aos 30 dias após o plantio, as manifestações epígeas foram contadas, sendo os valores expressos em percentagem de brotação em relação ao número de tubérculos plantados.

Os dados referentes à parte aérea da tiririca foram submetidos ao teste $t$, contrastandose as médias dos tratamentos entre os sistemas de manejo do solo e das finalidades de uso do milho, a $5 \%$ de probabilidade. Quanto à análise do banco de tubérculos, foi utilizada a estatística descritiva. Os dados climatológicos durante a condução do experimento estão apresentados na Figura 1.

\section{RESULTADOS E DISCUSSÃo}

Observou-se redução significativa da população de tiririca no plantio direto, em relação ao plantio convencional, tanto no milho cultivado para grão e silagem quanto no feijoeiro, em todas as épocas avaliadas (Tabelas 1, 2 e 3). A maior ocorrência de tiririca observada no plantio convencional, em relação ao plantio direto, pode ser atribuída ao revolvimento do solo, cujo efeito sobre essa espécie favorece sua propagação e seu estabelecimento (Godoy et al., 1995; Ferreira et al., 2000), ao passo que no plantio direto, além do não-revolvimento do solo, ocorreu o efeito da dessecação com glyphosate e 2,4-D. Na Tabela 1, verifica-se redução do número de manifestações epígeas de 93 e $87 \%$ aos 20 DAE e 84 e $80 \%$ aos 55 DAE no plantio direto de milho para grão e silagem,

Planta Daninha, Viçosa-MG, v.21, n.1, p.89-95, 2003 
respectivamente, comparado com o plantio convencional. De acordo com Milles et al. (1996), esse comportamento observado aos 20 DAE é explicado pela alta taxa de crescimento inicial da tiririca, proveniente do elevado número de indivíduos, e pela alta taxa de acumulação de biomassa por parte das manifestações epígeas iniciais. Aos 55 DAE, com o

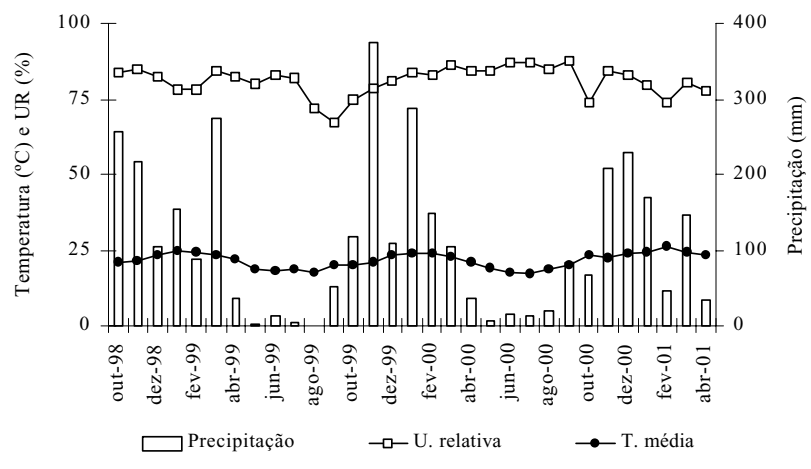

Figura 1 - Temperatura média $\left({ }^{\circ} \mathrm{C}\right)$, umidade relativa (UR\%) e precipitação mensal $(\mathrm{mm})$ durante o período do experimento. Viçosa-MG, 2001. fechamento da entrelinha pela cultura, observou-se redução da população. A tiririca é uma espécie de porte epígeo baixo e muito suscetível ao sombreamento; assim, acredita-se que a cobertura do solo tenha sido o fator primário de redução da população.

Verificou-se ainda redução da população de tiririca no plantio direto (Tabela 2), porém os valores foram inferiores aos encontrados na Tabela 1, provavelmente devido à distribuição da chuva (Figura 1). Segundo Zelaya et al. (1997), as maiores diferenças encontradas na população de tiririca entre sistemas de plantios direto e convencional são obtidas durante a estação chuvosa. Resultados semelhantes, no que se refere à redução da população de tiririca no plantio direto em relação ao convencional, foram também obtidos para o feijoeiro (Tabela 3).

O banco de tubérculos após a colheita do milho (ano agrícola 2000/01) foi maior no plantio convencional, comparado com o plantio direto, para ambas as finalidades de uso do milho (Figura 2). No plantio direto, em relação

Tabela 1 - Efeitos dos sistemas de manejo do solo (plantios convencional e direto) e das finalidades de uso do milho (grão e silagem) sobre a densidade e a biomassa da tiririca, avaliadas aos 20 e 55 DAE do milho, no segundo ano de condução do ensaio. Viçosa-MG, 2001

\begin{tabular}{|c|c|c|c|c|c|c|c|c|}
\hline \multirow{3}{*}{ Sistema de manejo } & \multicolumn{4}{|c|}{$20 \mathrm{DAE}^{1 /}$} & \multicolumn{4}{|c|}{$55 \mathrm{DAE}$} \\
\hline & \multicolumn{2}{|c|}{ Densidade $\left(\mathrm{n}^{\mathrm{o}} \mathrm{m}^{-2}\right)$} & \multicolumn{2}{|c|}{ Biomassa $\left(\mathrm{g} \mathrm{m}^{-2}\right)$} & \multicolumn{2}{|c|}{ Densidade $\left(\mathrm{n}^{\mathrm{o}} \mathrm{m}^{-2}\right)$} & \multicolumn{2}{|c|}{ Biomassa $\left(\mathrm{g} \mathrm{m}^{-2}\right)$} \\
\hline & Grão & Silagem & Grão & Silagem & Grão & Silagem & Grão & Silagem \\
\hline Plantio convencional & $1.468,75 \mathrm{Aa}^{2 !}$ & $1.910,42 \mathrm{Aa}$ & $217,8 \mathrm{Ab}$ & $295,37 \mathrm{Aa}$ & $556,94 \mathrm{Ab}$ & $763,89 \mathrm{Aa}$ & $146,81 \mathrm{Ab}$ & $238,26 \mathrm{Aa}$ \\
\hline Plantio direto & $109,72 \mathrm{Bb}$ & $247,92 \mathrm{Ba}$ & $12,92 \mathrm{Bb}$ & $23,34 \mathrm{Ba}$ & $89,58 \mathrm{Bb}$ & $149,31 \mathrm{Ba}$ & $25,32 \mathrm{Bb}$ & $28,03 \mathrm{Ba}$ \\
\hline
\end{tabular}

${ }^{1 /} \mathrm{DAE}=$ dias após a emergência. ${ }^{2 / /}$ Médias seguidas pela mesma letra não diferem entre si a $5 \%$ de probabilidade pelo teste t; as letras maiúsculas comparam as médias dos sistemas de manejo dentro de cada finalidade de uso do milho (colunas), e as minúsculas, as médias deste dentro de cada sistema de manejo (linhas).

Tabela 2 - Efeitos dos sistemas de manejo do solo (plantios convencional e direto) e das finalidades de uso do milho (grão e silagem) sobre a densidade e biomassa da tiririca, avaliadas aos 20 DAE do milho, no terceiro ano de condução do ensaio. Viçosa-MG, 2001

\begin{tabular}{|l|r|r|l|r|r|}
\hline \multirow{2}{*}{ Sistema de manejo } & \multicolumn{4}{|c|}{$20 \mathrm{DAE}^{1 /}$} \\
\cline { 2 - 6 } & \multicolumn{2}{|c|}{ Densidade $\left(\mathrm{n}^{\mathrm{o}} \mathrm{m}^{-2}\right)$} & \multicolumn{3}{c|}{ Biomassa $\left(\mathrm{g} \mathrm{m}^{-2}\right)$} \\
\cline { 2 - 7 } & \multicolumn{2}{|c|}{ Grão } & \multicolumn{2}{|c|}{ Silagem } & \multicolumn{2}{c|}{ Grão } & \multicolumn{2}{c|}{ Silagem } \\
\cline { 2 - 6 } & $677,08 \mathrm{Aa}^{2 /}$ & 548,00 & $\mathrm{Ab}$ & $267,62 \mathrm{Aa}$ & $180,46 \mathrm{Ab}$ \\
Plantio convencional & $38,89 \mathrm{Ba}$ & 25,00 & $\mathrm{Ba}$ & $9,27 \mathrm{Ba}$ & $7,44 \mathrm{Ba}$ \\
\hline
\end{tabular}

1/ DAE = dias após a emergência. ${ }^{2 /}$ Médias seguidas pela mesma letra não diferem entre si a 5\% de probabilidade pelo teste t; as letras maiúsculas comparam as médias dos sistemas de manejo dentro de cada finalidade de uso do milho (colunas), e as minúsculas, as médias destes dentro de cada sistema de manejo (linhas). 
ao convencional, a redução foi significativa nas três profundidades no milho para grão e silagem. Em ambos os sistemas de manejo do solo verificaram-se maiores números de tubérculos na camada superior; entretanto, prevaleceu o maior número no plantio convencional, onde os implementos de preparo rompem a dominância apical e dividem a cadeia de tubérculos, cujo efeito contribuiu para aumento da população dessa planta daninha, visto se tratar de uma espécie perene de propagação principalmente vegetativa. Resultados semelhantes sobre redução do banco de tubérculos de tiririca em plantio direto foram obtidos por Godoy et al. (1995) e Severich \& Franco (2000). Da mesma forma, verificou-se menor produção de biomassa dos tubérculos no plantio direto em relação ao convencional (Figura 3). Essa diminuição do número e da biomassa dos tubérculos se deveu à associação do controle químico realizado em todas as safras com glyphosate $+2,4$-D em pré-plantio, ao controle cultural exercido pela falta de revolvimento do solo e à adoção de culturas altamente competitivas, principalmente por luminosidade, como o milho e o feijão.

Neeser et al. (1998), no estudo de modelos da dinâmica populacional de tiririca, verificaram que, sob contínua rotação de milho e feijão, o controle de $95 \%$ do número de tubérculos resultou em densidades populacionais inferiores a 0,5 tubérculo $\mathrm{m}^{-2}$ durante o período de 18 meses. Segundo os autores, sob baixas densidades populacionais da tiririca, a extinção dos tubérculos no agroecossistema torna-se cada vez mais provável, devido aos efeitos ambientais e biológicos, que podem aumentar a mortalidade ou reduzir a produção de novos tubérculos.
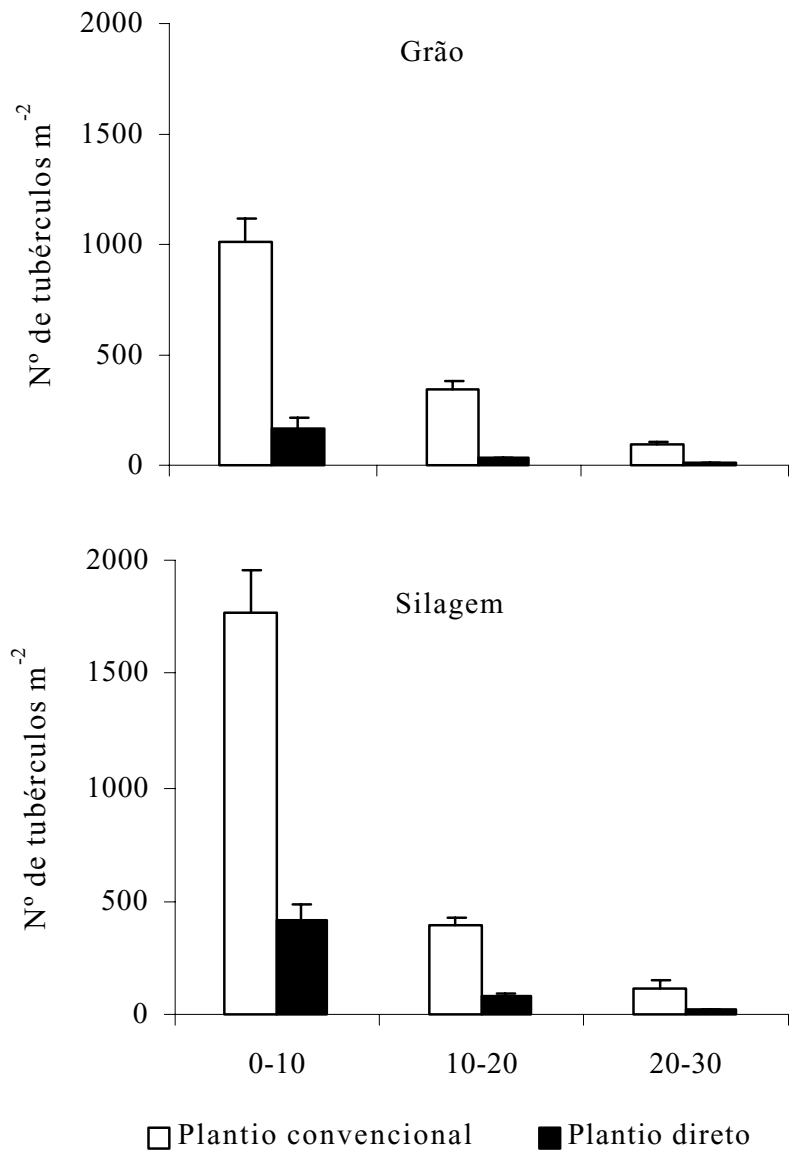

Figura 2 - Efeitos dos sistemas de manejo do solo (plantios convencional e direto) e das finalidades de uso do milho (grão e silagem) sobre o número de tubérculos coletados após a colheita do milho, no terceiro ano de condução, nas profundidades de $0-10,10-20$ e $20-30 \mathrm{~cm}$ (valores acompanhados do erro-padrão da média). Viçosa-MG, 2001.

A taxa máxima de brotação dos tubérculos coletados após o ciclo da cultura do milho foi obtida no sistema de plantio convencional, na profundidade de 0 a $10 \mathrm{~cm}$, com acentuada

Tabela 3 - Efeitos dos sistemas de manejo do solo (plantios convencional e direto) e das finalidades de uso do milho (grão e silagem) sobre a densidade e a biomassa da tiririca, avaliadas aos 20 e 40 DAE do feijão, no segundo ano de condução do ensaio. Viçosa-MG, 2001

\begin{tabular}{|l|r|r|r|r|r|r|r|r|}
\hline \multirow{3}{*}{ Sistema de manejo } & \multicolumn{4}{|c|}{$20 \mathrm{DAE}^{1 /}$} & \multicolumn{4}{|c|}{$40 \mathrm{DAE}$} \\
\cline { 2 - 9 } & \multicolumn{1}{|c|}{ Densidade $\left(\mathrm{n}^{\mathbf{0}} \mathrm{m}^{-2}\right)$} & \multicolumn{1}{|c|}{ Biomassa $\left(\mathrm{g} \mathrm{m}^{-2}\right)$} & \multicolumn{2}{c|}{ Densidade $\left(\mathrm{n}^{\mathbf{0}} \mathrm{m}^{-2}\right)$} & \multicolumn{3}{c|}{ Biomassa $\left(\mathrm{g} \mathrm{m}^{-2}\right)$} \\
\cline { 2 - 9 } & \multicolumn{1}{|c|}{ Grão } & \multicolumn{1}{|c|}{ Silagem } & \multicolumn{1}{|c|}{ Grão } & \multicolumn{1}{c|}{ Silagem } & \multicolumn{1}{c|}{ Grão } & \multicolumn{1}{c|}{ Silagem } & \multicolumn{1}{c|}{ Grão } & Silagem \\
\hline Plantio convencional & $497,22 \mathrm{Ab}^{2 /}$ & $688,89 \mathrm{Aa}$ & $24,41 \mathrm{Ab}$ & $38,05 \mathrm{Aa}$ & $811,11 \mathrm{Aa}$ & $1098,61 \mathrm{Aa}$ & $79,55 \mathrm{Ab}$ & $109,72 \mathrm{Aa}$ \\
Plantio direto & $18,06 \mathrm{Ba}$ & $19,44 \mathrm{Ba}$ & $0,54 \mathrm{Ba}$ & $0,86 \mathrm{Ba}$ & $51,39 \mathrm{Ba}$ & $63,19 \mathrm{Ba}$ & $2,99 \mathrm{Ba}$ & $4,92 \mathrm{Ba}$ \\
\hline
\end{tabular}

${ }^{1 /}$ DAE = dias após a emergência. $\stackrel{2}{2}$ Médias seguidas pela mesma letra não diferem entre si a $5 \%$ de probabilidade pelo teste t; as letras maiúsculas comparam as médias dos sistemas de manejo dentro de cada finalidade de uso do milho (colunas), e as minúsculas, as médias deste dentro de cada sistema de manejo (linhas). 
queda à medida que os tubérculos foram coletados de amostras mais profundas (Figura 4). Não se observou brotação de tubérculos coletados em área de plantio direto nas amostras provenientes de milho para grão, provavelmente por estes se apresentarem dormentes. No entanto, verificou-se brotação dos tubérculos coletados em área proveniente do plantio direto de milho para silagem até a profundidade de 0 a $20 \mathrm{~cm}$, embora tenha ocorrido em proporções inferiores às do plantio convencional. A brotação dos tubérculos no plantio direto proveniente de milho para silagem, comparado ao milho para grão, pode estar associada à ausência de palhada neste sistema, que poderá ter ocasionado maiores oscilações de temperatura do solo, favorecendo a brotação.
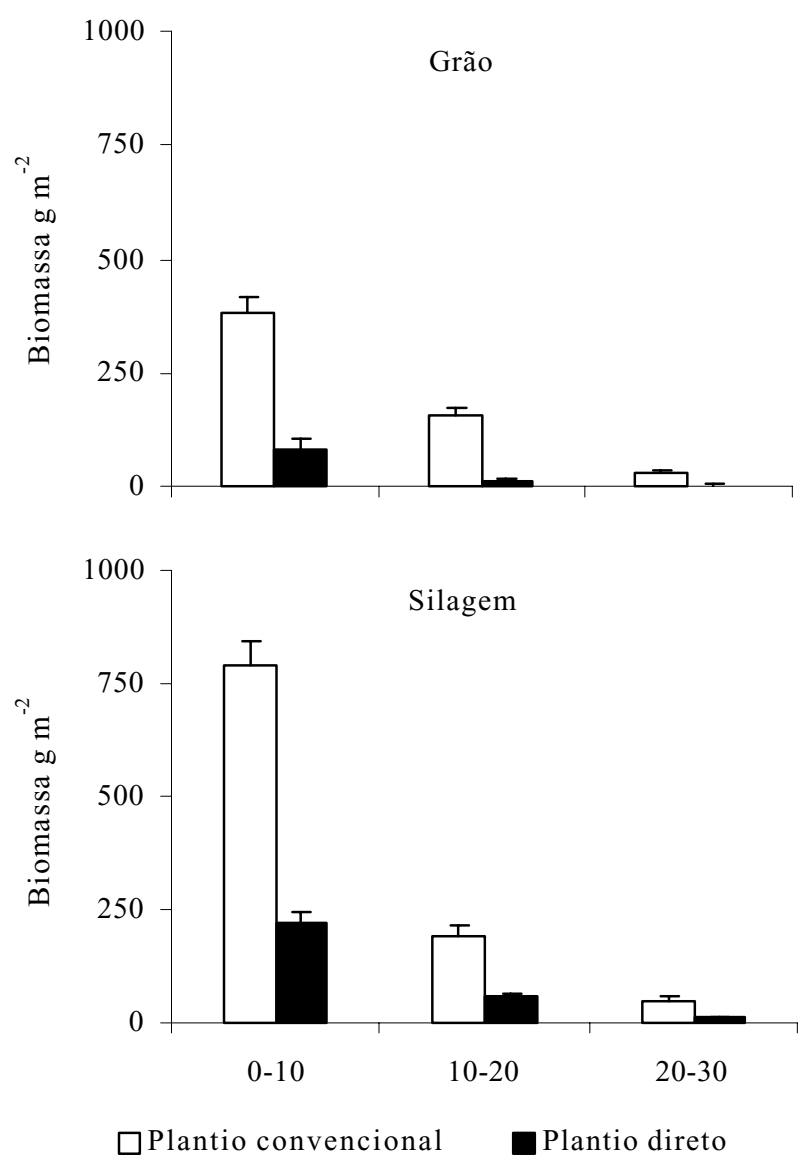

Figura 3 - Efeitos dos sistemas de manejo do solo (plantios convencional e direto) e das finalidades de uso do milho (grão e silagem) sobre a biomassa de tubérculos coletados após a colheita do milho, no terceiro ano de condução, nas profundidades de 0-10,10-20 e 20-30 cm (valores acompanhados do erro-padrão da média). Viçosa-MG, 2001.
A temperatura do solo, segundo Miles et al. (1996) e Sun \& Nishimoto (1997), é um dos principais fatores ambientais que afetam a brotação dos tubérculos de tiririca quando a umidade do solo é adequada. Miles et al. (1996), estudando os efeitos da temperatura na brotação de tubérculos de tiririca, verificaram que a taxa de brotação dos tubérculos aumentou linearmente com temperaturas constantes (66\%), porém a brotação dos tubérculos foi máxima (100\%) onde houve alternância de temperatura. De acordo com Tormenta (1995), a presença de palhada na superfície do solo reduz a incidência dos raios solares e evita a alternância de temperatura do solo; na ausência, o aumento das oscilações de temperatura é maior próximo à superfície do solo e decresce em profundidade (Rubin \& Benjamin, 1984).
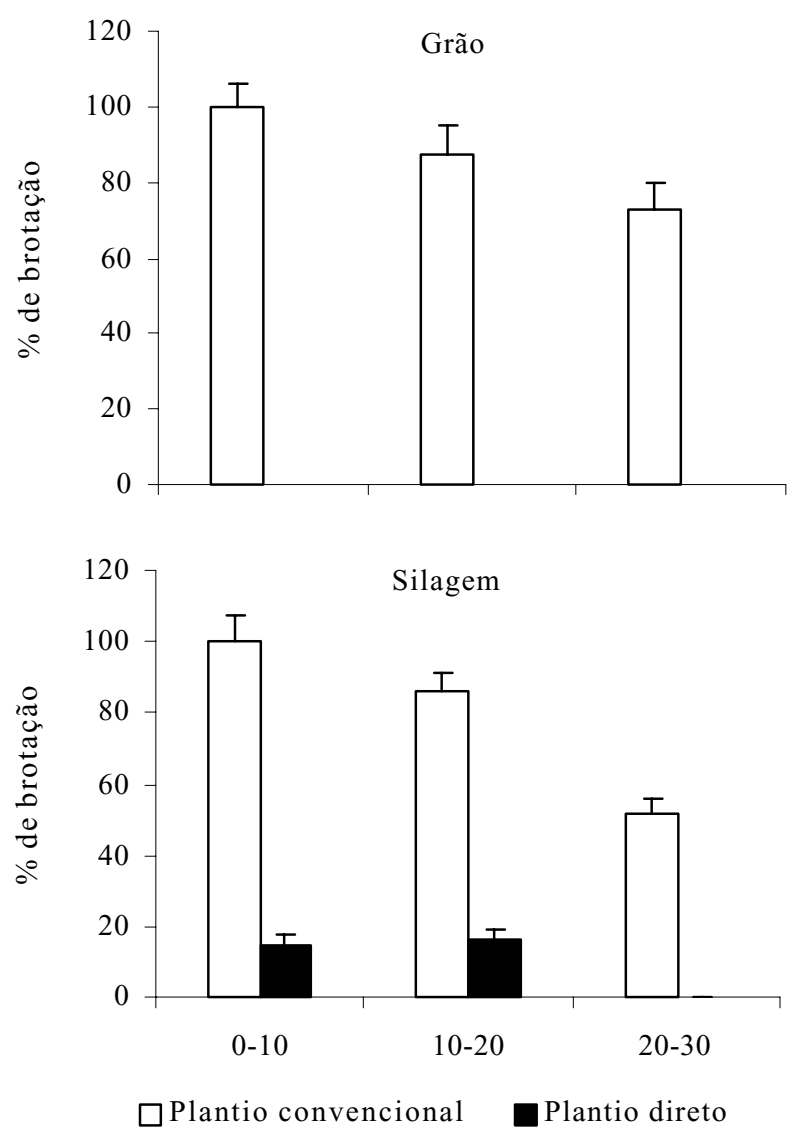

Figura 4 - Efeitos dos sistemas de manejo do solo (plantios convencional e direto) e das finalidades de uso do milho (grão e silagem) sobre a porcentagem de brotação dos tubérculos aos 30 dias após o plantio proveniente da coleta no campo, depois da colheita do milho, no terceiro ano de condução, nas profundidades de 0-10, 10-20 e 20-30 cm (valores acompanhados do erro-padrão da média). Viçosa-MG, 2001. 
Assim, surge a hipótese de que a dormência existente nos tubérculos encontrados no solo sob plantio direto pode ser causada pela presença de tubérculos mais velhos neste sistema de manejo, uma vez que a geração de novos tubérculos no plantio direto é menor em relação ao convencional, devido à ausência de revolvimento do solo e ao uso contínuo de dessecantes. Segundo Neeser et al. (1997, 1998), a idade dos tubérculos é um fator determinante da dormência dos tubérculos de tiririca e a proporção de tubérculos dormentes dentro da população aumenta com a idade. Conforme, os autores, a sobrevivência dos tubérculos sob baixas densidades durante dado intervalo de tempo depende da probabilidade de morte durante esse período, a qual espera-se aumentar com a idade, em razão de uma perda gradual da integridade fisiológica. Rottevell \& Naber (1993) relatam que observações sobre a sobrevivência de tubérculos de Cyperus esculentus indicam que a maioria da população morre dentro de dois anos, porém uma pequena fração sobrevive por período superior a seis anos.

Outra hipótese pode ser a translocação do glyphosate em subdoses até os tubérculos, podendo induzir a dormência destes, principalmente os mais distantes na cadeia subterrânea. Em síntese, no plantio direto, a manutenção da população de tubérculos pode permanecer baixa dentro de um limite imposto pelo regime de manejo adotado, até que os efeitos biológicos e ambientais causem a morte dos tubérculos remanescentes.

\section{LITERATURA CITADA}

CUDNEY, D. Nutsedge: history, economy, importance and distribution. In: NUTSEDGE Management Workshop. Riverside: University of California, 1997. (http:// www.cnas.ucr.edu/ bps/hnutsedge.htm.)

FERREIRA, F. A. et al. Manejo integrado de plantas daninhas em hortaliças. In: MANEJO integrado de doenças, pragas e plantas daninhas. Viçosa: Universidade Federal de Viçosa, 2000. p. 365-372.

FREITAS, R. S. et al. Efeitos do flazassulfuron e do glyphosate em aplicações única e seqüencial sobre o controle da tiririca (Cyperus rotundus). Ceres, v. 44, n. 256, p.597-603, 1997.

GODOY, G.; VEGA, J.; PITTY, A. El tipo de labranza afecta la flora y la distribución vertical del banco de semillas de malezas. Ceiba, v. 36, n. 2, p. 217-229, 1995.
MCLACHLAN, S. M. et al. Effect of corn induced shading on dry matter accumulation, distribution, and architecture of redroot pigweed (Amaranthus retroflexus). Weed Sci., v. 41 , p. $568-573,1993$.

MILES, J. E.; NISHIMOTO, R. K.; KAWABATA, O. Diurnally alternating temperatures stimulates sprouting of purple nutsedge (Cyperus rotundus) tubers. Weed Sci., v. 44, p. 122-125, 1996.

NEESER, C.; AGÜERO, R.; SWANTON, C. L. A mechanistic model of purple nutsedge (Cyperus rotundus) population dynamics. Weed Sci., v. 46, p. 673-681, 1998.

NEESER, C.; AGÜERO, R.; SWANTON, C. L. Survival and dormancy of purple nutsedge (Cyperus rotundus) tubers. Weed Sci., v. 45, p. 784-790, 1997.

ROTTEVELL, A. J. W.; NABER, H. Decline in yellow nutsedge (Cyperus esculentus) when tuber formation is prevented. In: BRIGHTON CROP PROTECTION CONFERENCE WEEDS, 1993, Farnham. Proceedings... Farnham: 1993. p. 311-316.

RUBIN, B.; BENJAMIN, A. Solar heating of the soil: involvement of environmental factors in the weed control process. Weed Sci., v.32, p. 138-142, 1984.

SANTOS, B. M. et al. Effects of shading on the growth of nutsedges (Cyperus spp). Weed Sci., v. 45, p. 670-673, 1997.

SEVERICH, J.C.; FRANCO, P. No-till and glyphosate reduce the emergence and tuber bank of Cyperus rotundus. In: INTERNATIONAL WEED SCIENCE CONGRESS, 3., 2000. Foz do Iguaçu. Abstracts... Foz do Iguaçu: IWSS, 2000. p. 13.

SILVA, A. A. et al. Controle de plantas daninhas. In: ASSOCIAÇÃO BRASILEIRA DE EDUCAÇÃO SUPERIOR - ABEAS. Curso de proteção de plantas Módulo 3. Brasília, 2001, 260 p.

SIRIWARDANA, G.; NISHIMOTO, R. K. Propagules of purple nutsedge (Cyperus rotundus) in soil. Weed Technol., v. 1, n. 3, p. 217-220, 1987.

SUN, W; NISHIMOTO, R, K. Dormancy release of purple nutsedge tuber buds by a single thermal pulse. J. Am. Soc. Hortic. Sci., v. 122, n. 3, p. 306-309, 1997.

TORMENTA, C. A. Resíduos culturais: efeitos no controle da erosão em alterações em propriedades físicas do solo. In: CURSO SOBRE MANEJO DO SOLO NO SISTEMA DE PLANTIO DIRETO. Castro: Fundação ABC, 1995. p. 3146.

ZELAYA, I. A.; OVEN, M. D. K.; PITTY, A. Effect of tillage and environment on weed population dynamics in the dry tropics. Ceiba, v. 38, n. 2, p. 123-135, 1997.

Planta Daninha, Viçosa-MG, v.21, n.1, p.89-95, 2003 